\section{English Series}

(C) Springer-Verlag Berlin Heidelberg \& The Editorial Office of AMS 2015

\title{
Erratum to: Existence of T-solution for Degenerated Problem via Minty's Lemma
}

\author{
Y. AKDIM E. AZROUL M. RHOUDAF \\ Département de Mathématiques et Informatique \\ Faculté des Sciences Dhar-Mahraz B. P 1796 Atlas Fès, Maroc \\ E-mail:akdim@yahoo.fr_azroul@yahoo.fr_rhoudaf_mohamed@yahoo.fr
}

\section{Erratum to: Acta Mathematica Sinica, English Series}

DOI: $10.1007 / \mathrm{s} 10114-007-0970-4$

The original version of this article unfortunately contained a mistake. The spelling of the first author's name was incorrect. The correct spelling is Y. AKDIM.

The online version of the original article can be found at

http://dx.doi.org/10.1007/s10114-007-0970-4 
